\title{
LA PRUEBA ILÍCITA EN LA ERA DIGITAL
}

\author{
ASPECTOS PROCESALES DE UN PROBLEMA TRADICIONAL \\ CON CONTENIDO NUEVO EN EL MARCO DEL PROCESO \\ LABORAL DE CÓRDOBA
}

POR LAURA NIEVAS ${ }^{1}$

\begin{abstract}
SUMARIO: I. INTRODUCCIÓN. II. LA PRUEBA: SU ALCANCE Y SUS LÍMITES: a) Aspectos conceptuales de la "prueba". b) Alcances del derecho a probar. III. PRUEBA ILÍCITA: a) Prueba prohibida y prueba ilícita. b) Regla de la exclusión probatoria, su alcance y fundamentos. c) Inadmisibilidad, nulidad y exclusión probatoria. IV. EL CASO DEL PROCESO LABORAL DE CÓRDOBA: a) Momentos en que pueden presentarse los planteos sobre prueba ilícita: i) Inadmisibilidad. ii) Decreto de prueba: recursos. iii) Incidencias durante la producción del medio de prueba. iv) Exclusión probatoria. v) Nulidad de la sentencia vía recurso de casación. $V$. CONCLUSIONES. VI) BIBLIOGRAFÍA CONSULTADA.
\end{abstract}

\section{I.- Introducción}

En las últimas décadas, el desarrollo y masificación de las tecnologías de la información y de la comunicación (TIC) ha impactado en el modo de vivir y de relacionarnos. La generalidad de los especialistas, de diversas áreas del conocimiento, estudia este fenómeno y sus efectos, en tanto se trata de un problema transversal que incide en todo tipo de prácticas y organizaciones, y el ordenamiento jurídico no es ajeno a ello.

En la praxis procesal, teniendo en cuenta el contenido de las pretensiones que llegan al fuero del trabajo y como una manifestación del impacto tecnológico en el mundo del trabajo, se han tornado habituales los planteos que guardan relación con la incorporación de elementos y producción de medios de prueba ligados al uso de las TIC, por lo que han adquirido notable interés los presupuestos que hacen a la eficacia y validez de la prueba.

Por otro lado, en el marco de los debates sobre la efectividad de los derechos constitucionales en el proceso, la actividad probatoria está siendo objeto de especial atención dado que en los ordenamientos jurídicos actuales la facultad de presentar pruebas forma parte del contenido de la garantía de acceso a la justicia y del derecho de defensa, pues la posibilidad de probar los hechos en que se apoyan las pretensiones de las partes es condición necesaria para su efectividad.

\footnotetext{
1 *Doctoranda de la Universidad Pablo de Olavide, Sevilla; Magister en Derecho y Argumentación Jurídica. Facultad de Derecho y Ciencias Sociales, UNC; Especialista en Investigación en Ciencias Sociales, Jurídicas y Políticas, Universidad Pablo de Olavide, Sevilla-España; Abogada, Facultad de Derecho y Ciencias Sociales, UNC.
} 
En este trabajo, desde la óptica del derecho procesal, en general, y del derecho procesal laboral, en particular, se identifican problemas relativos a la validez probatoria, cuando lo que se pretende incorporar o producir en el proceso son elementos probatorios informáticos $(E P I)^{2}$, y se analizan las vías procesales previstas para su tratamiento en el ordenamiento laboral de Córdoba, con especial referencia a la exclusión probatoria.

\section{La prueba: su alcance y sus límites \\ a) Aspectos conceptuales de la prueba}

A los efectos didácticos es necesario clarificar algunos aspectos conceptuales. En este sentido, el término "prueba" posee carácter polisémico, es decir puede ser empleado para hacer referencia a cuestiones diferentes.

Dado que sus acepciones no siempre son empleadas en igual sentido deviene necesario explicitar el modo en que la noción será utilizada.

Teniendo en cuenta los momentos de la actividad probatoria Gascón Abellán ${ }^{3}$ distingue entre: medios de prueba, procedimiento probatorio y resultado del procedimiento probatorio. Medio de prueba denota todo aquello que permite conocer los hechos relevantes de la causa; procedimiento probatorio, la actividad del intelecto (constatación o inferencia) mediante la cual, a partir de los medios de prueba, se conocen los hechos relevantes para la resolución, y resultado probatorio la información que se obtiene a partir de los medios de prueba.

En la doctrina especializada se encuentra, además, un cuarto uso de la noción: prueba como elemento probatorio, para sindicar a la información que se pretende ingresar al proceso ${ }^{4}$, lo que puede coincidir con la denominación del medio de prueba en la medida que ese medio se encuentre receptado normativamente ${ }^{5}$.

En este trabajo, empleará, fundamentalmente, el término prueba a secas en su tercera acepción, esto es para referir al resultado probatorio y en el resto de los usos se tratará de especificar el sentido en que se está empleando el término.

\section{b) Alcances del derecho a probar}

A partir de un análisis cronológico de los sistemas jurídicos, es posible evidenciar que, durante mucho tiempo, el modo en que se resolvían los conflictos judiciales no constituía una preocupación importante ${ }^{6}$ y que a raíz de profundos cambios políticos, sociales

\footnotetext{
2 Con esta noción se designa a toda aquella información generada, transmitida o almacenada por medios técnicos..

3 GASCÓN ABELLÁN, Marina. Los hechos en el derecho, Marcial Pons, Madrid, 2004, p. 83-85.

4 En los sistemas del common law los conceptos evidence (elemento de prueba) y proof (resultado probatorio) clarifican la distinción entre, por un lado, los datos, la información, las circunstancias, los documentos, los enunciados y los conocimientos que pueden ser usados como premisas de la decisión relacionada con los hechos litigiosos y, por otro, las conclusiones alcanzadas o resultados generados a través de las inferencias extraídas, que dan como resultado enunciados sobre la existencia de los hechos litigiosos y la verdad de esos enunciados. Sin embargo, esa dicotomía no siempre es lo suficientemente clara en la terminología del derecho continental, donde se usan similares términos tanto para la premisa como para la conclusión del razonamiento probatorio, por lo que los enunciados formulados en ese lenguaje necesitan, constantemente, ser interpretados apelando al contexto. TARUFFO, M. La prueba, Marcial Pons,Madrid, 2008, p.34.

5 Por ejemplo, cuando se ofrece un documento particular (art.287 CCCN): el medio probatorio es la prueba documental (241-254 CPCC); el resultado la información que proporcione a efectos de corroborar las proposiciones afirmadas por las partes, mientras que el elemento probatorio es el documento en sí, ya sea que posea un soporte material o inmaterial (carta, correo electrónico, etc.).

6 Así, de consultarse el procedimiento civil romano surge que el tormento como medio para obtener un testimonio era conocido y empleado en ese sistema, institución que, con una reglamentación minuciosa, permanece en el proceso civil italiano hasta entrado el siglo XX. SCIALOJA en KIELMANOVICH, Jorge. "Algo más sobre la ineficacia de la prueba ilícita". Cita on line: 0003/008557 20013501.txt. Doctrina.
} 
y jurídicos que tienen lugar en occidente desde finales del siglo XVIII el proceso judicial evoluciona hasta convertirse en un delicado instrumento enderezado a la tutela de derechos fundamentales.

Esto, especialmente, a partir de la inclusión en los textos constitucionales del derecho a la jurisdicción, a probar o al contradictorio, entre otros, por lo que en los ordenamientos actuales la facultad de presentar pruebas relevantes forma parte del contenido de la garantía de acceso a la justicia y del derecho de defensa, pues la oportunidad de probar los hechos que apoyan las pretensiones de las partes es condición necesaria para su efectividad.

Sin embargo, también, se han establecido reglas tendientes a regular la admisibilidad o exclusión de ciertos elementos o resultado probatorio, lo cual impide a las partes presentar un amplio abanico de pruebas, situación que se torna compleja cuando tales previsiones han sido dispuestas a efectos de proteger otros derechos. En palabras de Gascón Abellán, la institucionalización del proceso incorpora importantes excepciones a la regla de averiguación de los hechos estableciendo limitaciones respecto de los medios o de las fuentes de prueba.

Éstas, según su valor epistemológico, pueden distinguirse en: limitaciones que coadyuvan a la averiguación de la verdad, en tanto minusvaloran pruebas con bajo valor gnoseológico ${ }^{7}$, o bien dirigidas a asegurar la tutela de determinados valores extraprocesales que se consideran relevantes, algunas, incluso, tienen sustento en normas del ius cogens como es la proscripción de la tortura y de la eficacia de cualquier prueba obtenida a través de tormentos. ${ }^{8}$

Luego, si bien, la exclusión de esta clase de pruebas es conditio sine qua non para cualquier proceso y no corresponde su consideración aun de no existir reglas positivas en tal sentido", pueden presentarse otros supuestos en los cuales la vulneración no surge de modo patente, lo que incide, desde lo procesal, en el tratamiento a efectuárseles y, desde los sustancial, nos coloca frente al problema de cómo resolver colisiones entre derechos constitucionales.

Finalmente, todo acto que implique la adquisición de prueba (admisión o producción) estará en relación, por un lado, con los fines del proceso que se trate, conforme a los bienes en juego o el grado de intervención del Estado (proceso civil, laboral o penal) $y$, por otro, con los derechos y garantías reconocidos constitucional para proteger a la persona humana.

\footnotetext{
7 En la generalidad de los ordenamientos procesales se establecen normas que contribuyen a restringir el ofrecimiento de elementos probatorios con mínimo valor gnoseológico, y que, en la práctica, contribuyen a la celeridad del proceso. En este sentido, en el CPCC se establece que "Serán inadmisibles las pruebas que sean manifiestamente improcedentes, inconducentes, meramente dilatorias (...)” (art.199). Similar disposición se encuentra en el CPCCN, al disponer que: "No podrán producirse prueba sino sobre hechos que hayan sido articulados por las partes en sus escritos respectivos. No serán admitidas las que fueren manifiestamente improcedentes o superfluas o meramente dilatorias" (art.364).

8 Convención contra la Tortura y otros Tratos o Penas Crueles, Inhumanos o Degradantes. Adoptada por la Asamblea General de las Naciones Unidas con fecha 10/12/1984 (Resolución 39/46). En vigor desde 26/06/1987 (art.15). En sentido similar, Convención Interamericana para Prevenir y Sancionar la Tortura (art.10) adoptada por la Asamblea General de la OEA el 12/09/1985. En vigor desde:28/2/1987. Argentina deposita el instrumento el 31/3/1989.

9 JARA BUSTOS, Francisco, "Prueba ilícita en materia laboral, la regla de exclusión más amplia del derecho chileno" (p. 113 a 128), en Revista Chilena de Derecho del Trabajo y de la Seguridad Social, Vol. 2, Nº3, 2011, p.116.
} 


\section{Prueba ilícita}

La actividad probatoria -como se ha expresado- se desarrolla en un marco institucionalizado de normas que condicionan la búsqueda de la verdad, lo cual trae aparejado, al menos, dos líneas de análisis: por un lado, una tendiente a dilucidar el contenido y alcance de aquellas normas que al prohibir ciertos medios o declarar ineficaces elementos de prueba limitan el derecho a probar.

Por otro, una dirigida a clarificar algunas inquietudes de orden procesal que se generan a partir de la prueba ilícita, las que giran en torno al alcance de los institutos previstos en el ordenamiento procesal (inadmisibilidad, nulidad o exclusión), para resolver planteos relativos al derecho a probar y sus restricciones.

La respuesta a este planteo depende del modo en que la cuestión haya sido regulada en el proceso que se trate (civil, familia, laboral, etc.) con el agregado que en Argentina, debido al sistema federal de gobierno, en cada provincia esta regulación, de existir, puede tener diferentes alcances. En el caso, nos ocupamos de la respuesta brindada por el ordenamiento procesal laboral de Córdoba tomando en consideración, a los fines didácticos, el momento en que las previsiones normativas operan.

\section{a) Prueba prohibida y prueba ilícita}

La doctrina ha empleado diferentes nociones para referirse a los elementos probatorios que han sido admitidos o producidos durante el proceso sin respetar derechos o garantías constitucionales o, bien, normas sustanciales o procesales que los reglamentan.

En este sentido, Midón ${ }^{10}$ entiende que la noción prueba prohibida comprende a todo elemento que contribuye a demostrar un hecho, que ha sido obtenido violando o contradiciendo una norma legal o un principio de derecho positivo, mientras que con la noción prueba ilícita refiere a la adquisición o práctica de una prueba comprometiendo una norma o principio constitucional o instrumento internacional de igual jerarquía.

A su vez, distingue el efecto que uno u otro caso acarrea, e indica que cuando media una violación de normas legales o procesales, sin vulnerar derechos fundamentales, se estaría ante un supuesto de nulidad; en cambio cuando se viola un derecho constitucional o una norma legal que tenga por objeto la protección de libertades públicas o derechos personalísimos se estaría ante un acto inexistente.

Distinciones análogas se han efectuado en el derecho comparado. Así Carocca Pérez" considera prueba ilícita a la obtenida en infracción de cualquier derecho fundamental reconocido constitucionalmente, y prueba irregular o ilegal a la obtenida 0 practicada vulnerando preceptos que no gozan del carácter de normas constitucionales que reconocen derechos fundamentales, incluyendo bajo esta denominación las fuentes de pruebas logradas de modo ilegal, como, también, los medios de prueba practicados sin observar el procedimiento establecido, siempre que a raíz de tales infracciones no se hayan afectado derechos fundamentales. 
Por su parte, Gascón Abellán², refiriendo al ordenamiento español, entiende por prueba ilícita la que se obtiene vulnerando garantías constitucionales (inviolabilidad del domicilio o secreto de las comunicaciones), infringiendo derechos constitucionales (derecho de defensa) o a través de medios que la constitución prohíbe expresamente o no autoriza. Afirma, además, que la prohibición de la prueba ilícita no requiere de regulación expresa, consecuencia que deriva de la especial resistencia de los derechos fundamentales frente a los actos de poder contrarios a ellos y de la necesidad de anular los efectos que tales actos pudiesen generar.

En cuanto a su alcance, Minvielle ${ }^{13}$ entiende que la categoría prueba ilícita integra el género pruebas prohibidas, donde se encuentran otras distinciones como la prueba irritual, prohibida expresamente o deducida del sistema.

En síntesis, si bien se trata de distinciones que no poseen una aceptación unánime y a medida que se consultan autores aparecen otras sistematizaciones, es posible distinguir, al menos, un criterio restrictivo y su opuesto. Los autores que se sitúan en el primero, entienden que hay prueba ilícita cuando se ha inobservado una garantía fundamental, mientras que quienes lo hacen en el criterio amplio consideran que hay prueba ilícita cuando aquélla ha sido obtenida o producida contraviniendo una norma de derecho, con independencia de su jerarquía.

En este trabajo, la noción prueba ilícita es empleada como comprensiva de la obtención de elementos de prueba o de la producción de medios de prueba contraviniendo normas de jerarquía constitucional, y comprendida, a su vez, por la categoría pruebas prohibidas, como una especie de éstas, dado que entre unas y otras es posible trazar una relación de especie a género. ${ }^{14}$

\section{b) Regla de la exclusión probatoria, su alcance y fundamentos}

Vinculada a las limitaciones probatorias, la regla de exclusión se desarrolla, inicialmente, mediante la jurisprudencia y, más adelante, alcanza recepción normativa en algunos ordenamientos jurídico-procesales. Propende a la exclusión del resultado probatorio que ha ingresado al proceso infringiendo previsiones normativas en su adquisición o, bien, del material obtenido en infracción durante la producción del medio de prueba, por lo que opera con posterioridad a la admisión de la prueba.

En cuanto a sus efectos, implica la invalidez de los elementos probatorios obtenidos o producidos en violación de derechos o garantías constitucionales, como la transmisión de ese efecto a aquella información que sea su consecuencia (doctrina del fruto del árbol envenenado o del efecto reflejo de la prueba ilícita).

Se trata de una creación pretoriana, que tuvo su génesis en la jurisprudencia norteamericana de finales del siglo $X \mathrm{X}^{15}$, y que en las últimas décadas ha alcanzado reconocimiento en el derecho positivo, lo que evidencia la importancia que presenta la

\footnotetext{
12 GASCÓN ABELLÁN, ob. cit., p. 132/133.

13 Citada por HAIRABEDIÁN, Maximiliano, Eficacia de la prueba ilícita y sus derivaciones en el proceso penal, Ad Hoc, Buenos Aires,2016, p. 36.

14 Pellegrini GrinOVER, Ada, "Pruebas ilícitas”, en Derecho Penal. Derecho Procesal Penal, Abeledo Perrot, Buenos Aires, 1997, p. 306.

15 En Argentina si bien la jurisprudencia se expidió al respecto de modo contemporáneo a la estadounidense, en el caso "Charles Hnos.", la cuestión no volvió a ser tratada hasta casi un siglo después, cuando la CSJN resuelve la causa "Montenegro" (1981). Es posible ampliar en HAIRABEDIÁN, ob. cit..
} 
licitud de la prueba tanto a nivel local ${ }^{16}$ como internacional ${ }^{17}$.

Los fundamentos que la sustentan son variados, y pueden encontrarse tanto de índole práctico como ético o moral. Ni la doctrina ni la jurisprudencia han alcanzado consenso al respecto, a pesar de tratarse de una cuestión importante para determinar los alcances -como sus excepciones- de esta institución que en la praxis procesal es una de las vías empleadas para aplicación de normas que limitan la actividad probatoria.

Por un lado, se destaca el justificativo preventivo, de arraigada tradición en la jurisprudencia estadounidense, cuyo argumento radica en que al excluir una prueba ilícita se desincentivan las conductas negativas del personal policial o de los miembros de los organismos de investigación. ${ }^{18}$

Por otro, el argumento axiológico, propio del ámbito nacional, conforme el cual, en términos de la CSJN -en varias oportunidades-, otorgar valor al resultado de un delito y apoyar sobre él una sentencia judicial no sólo es contradictorio con el reproche formulado, sino que compromete la buena administración de la justicia al pretender constituirla en beneficiaria de un hecho ilícito. ${ }^{19}$

La doctrina, también, emplea estos argumentos. Así, Morello ${ }^{20}$ refiere que conceder valor a pruebas obtenidas por vías ilegítimas y apoyar en ellas una sentencia suscita un conflicto moral y compromete la buena administración de justicia. En sentido similar, Devis Echandía ${ }^{21}$ ha expresado que se civiliza la justicia, porque no puede aceptarse que la lucha procesal sea como una guerra en la cual el fin justifique los medios, de manera que se pueda acudir a las peores atrocidades con el pretexto de querer encontrar la verdad. ${ }^{22}$

\section{c) Inadmisibilidad, nulidad y exclusión probatoria}

Estos institutos si bien tienen en común la no consideración en el proceso judicial de ciertos hechos o actos procesales cuando se han inobservado normas, tanto formales como sustanciales, lo cierto es que son diferentes y en el iter procesal se presentan, también, en momentos diferentes.

Así, la inadmisibilidad de los elementos probatorios o medios de prueba ofrecidos implica su no ingreso al proceso, y se relaciona con la oportunidad procesal en que aquéllos se ofrecen o con su legalidad. Esto es, un elemento probatorio es inadmisible cuando se halla prohibido por la ley o es ofrecido fuera de los plazos legales.

\footnotetext{
16 Constitución de la Ciudad de Buenos Aires (art.13) y códigos procesales penales de Córdoba (art.194), Buenos Aires (art.211), Mendoza (art.207), etc. 17 Estatuto de la Corte Penal Internacional (art. 69 inc.7).

18 En Estados Unidos, hay quienes indican, especialmente, a partir del caso "Hudson v/ Michigan 547 U.S. 586 (2006)", un declive de la regla de exclusión probatoria en tanto haberse considerado el efecto que implican medidas civiles o disciplinarias para disuadir el accionar de los agentes estatales.

19 CSJN en autos "Ruiz" y "Montenegro", entre otros.

20 Citado por QUADRI, ob. cit.

21 Ídem nota anterior.

22 El esclarecimiento de los hechos punibles no sujeto al límite alguno entrañaría el peligro de destruir muchos valores colectivos e individuales. ROXIN citado en HAIRABEDIÁN, ob. cit., p. 55.
} 
Por su parte, la nulidad torna ineficaces los actos que se celebran en el proceso. Esto es, trae aparejada la privación de los efectos imputados a los actos procesales que adolecen de algún vicio en sus elementos esenciales y que, por ello, carecen de aptitud para cumplir el fin al que se hallan destinados..$^{23}$

Finalmente, la regla de exclusión probatoria implica la no valoración del resultado probatorio obtenido en violación de derechos y garantías constitucionales, así como la transición de ese efecto a la información obtenida como consecuencia de la primera. Luego, la exclusión probatoria, si bien presenta puntos de coincidencia con la nulidad, en tanto finalmente ambas acarrean la ineficacia del elemento probatorio que se trate, no son equiparables. Así, la nulidad abarca un abanico de actos procesales más amplio que la exclusión probatoria: los actos que tienen lugar durante todo el proceso no sólo aquéllos que se celebran durante la actividad probatoria.

No obstante, desde otra perspectiva, se puede considerar de mayor alcance a la regla de exclusión -en relación a la nulidad-, en tanto: comprende no sólo actos del proceso sino, también, los cumplidos fuera de él, y puede alcanzar la ineficacia de prueba que es consecuencia del material obtenido ilícitamente, lo que no siempre suele quedar atrapado por la nulidad. ${ }^{24}$

\section{El caso del proceso laboral de Córdoba}

La Ley Procesal del Trabajo (LPT) ${ }^{25}$ al tratar la prueba refiere a la inversión de la carga probatoria y a algunos medios de prueba (arts. 39-44), remitiendo al Código Procesal Civil y Comercial (CPCC) ${ }^{26}$ en aquellos supuestos no regidos por sus dispositivos (art.114). Asimismo, con la modificación introducida a la LPT por la ley 10.596 se faculta al juez a sustituir medios probatorios y, en el marco del proceso declarativo abreviado (PDA), en ciertas circunstancias, a declarar la inadmisibilidad de elementos probatorios (arts.53 y 83 sexies $^{27}$, respectivamente).

En relación al tema que nos ocupa, se ha previsto la inadmisibilidad de los elementos de prueba que estuvieren prohibidos (art.199 CPCC) ${ }^{28}$, igual previsión se ha dispuesto de modo especifico en la LPT para el caso del PDA (art. 83 sexies LPT).

Avanzando, en el iter probatorio, en contra de la resolución que deniegue o sustituya alguna prueba procede el recurso de reposición y apelación (art. 53 LPT). Esto es, ante un decreto de prueba que deniegue un el elemento probatorio ofrecido o la producción de un medio de prueba, la parte afectada tiene habilitada la vía recursiva.

\footnotetext{
23 PALACIO, Lino E., Código Procesal Civil y Comercial de la Nación, Abeledo Perrot, Buenos Aires, 2003, p. 327.

24 Desde el ámbito penal se proporciona como ejemplo la previsión del art 45 del Código Procesal Penal de Córdoba (CPPC) que si bien impide el allanamiento nocturno de morada, salvo excepciones, no sanciona con nulidad su violación, de allí que en virtud del sistema taxativo de las nulidades un registro de noche no autorizado y sus consecuencias no quedarían atrapados por la sanción de nulidad, aunque si lo estarían por la regla de exclusión. HAIRABEDIÁN, ob. cit., p. 75.

25 Ley 7987, B.O., 15/1/1991.

26 Ley 8465 , B.O., 8/6/1995.

27 Modificado e introducido, respectivamente, por la ley 10.596 modificatoria de la LPT cuya entrada en vigencia, prevista para junio de 2019, ha sido suspendida por 180 días, conf. ley 10.640 (B.O. ,28/6/2019).

28 En sentido similar en el CPCC de la Nación y en el CPCC de la provincia de Buenos Aires, al regular la actividad probatoria se establece que "La prueba deberá producirse por los medios previstos expresamente por la ley y por los que el juez disponga, a pedido de parte o de oficio, siempre que no afecten la moral, la libertad personal de los litigantes o de terceros, o no estén expresamente prohibidos para el caso. Los medios de prueba no previstos se diligenciarán aplicando por analogía las disposiciones de los que sean semejantes o, en su defecto, en la forma que establezca el juez" (art. 378 y 376 , respectivamente).
} 
En igual sentido, en el proceso civil, la resolución que admite la apertura a prueba o concede el despacho de diligencias probatorias no es apelable (art. 198 CPCCC) ${ }^{29}$. Esto se justifica en que de permitirse la apelación se daría una herramienta susceptible de dilatar indefinidamente la resolución final del proceso.

Precluida la admisibilidad, durante la producción de un medio de prueba las objeciones presentadas contra actos de los sujetos que intervienen en el proceso nos reconducen al ámbito de los incidentes. Estos constituyen la vía adecuada para plantear la nulidad de un acto procesal realizado en el curso de la instancia. ${ }^{30}$

En el proceso laboral el incidente de nulidad está previsto a efectos de cuestionar los vicios de procedimiento distintos a los contenidos en una resolución judicial (art.32 sgtes., LPT). Respecto a su interposición es necesario distinguir, conforme el momento cuando se produce el vicio: según tenga lugar en el marco de una audiencia -de conciliación o de vista de la causa- en cuyo caso el planteo corresponde sea interpuesto en ese acto, de los que tienen lugar en el resto del proceso en cuyo caso el planteo debe efectuarse a los seis días de conocido el acto viciado (art. 34, LPT).

La nulidad puede ser declarada a petición de parte, cuando quien la alegue se encuentre afectado y no haya producido o consentido el vicio o, bien, de oficio cuando el vicio implique la violación de normas constitucionales que produzca o pudiere producir un perjuicio irreparable (art. 33 LPT) ${ }^{31}$ y, en cuanto a su consecuencias, declarada hace desaparecer los efectos producidos por el acto viciado, e impide se sigan produciendo (art. 36 LPT), esto es posee efectos retroactivos al momento en que hubiera ocurrido el vicio y ultractivos, por carácter transitivo, a los actos que sean su consecuencia o se encuentren íntimamente ligados. ${ }^{32}$

\section{a) Momentos en que pueden presentarse los planteos sobre prueba ilícita}

De lo reseñado se evidencia que no hay disposiciones específicas en el ordenamiento procesal laboral sobre prueba ilícita, lo que lleva a preguntarse ¿Cómo encausar los planteos que se presenten? Para abordar este tópico, a efectos didácticos, se distingue conforme el momento procesal en que los planteos pueden presentarse.

\section{i) Inadmisibilidad}

En la etapa probatoria, con sustento en el derecho de defensa y la libertad probatoria se despachan favorablemente, en principio, todos los elementos y medios probatorios ofrecidos. Sin embargo, como se ha referido, en el CPCC y en la LPT -para el caso del PDA- se establece la inadmisibilidad de la prueba prohibida (arts. 199 CPCC y 83 sexies LPT).

En cuanto al alcance de estos enunciados normativos, esto es, qué queda comprendido como prueba prohibida, Díaz Villasuso ${ }^{33}$ refiere que se trata de supuestos determinados por las normas y, a modo de ejemplo, menciona: la prueba confesional en

\footnotetext{
29 Sin embargo, en la práctica se ha dado trámite a planteos cuando por una negligencia se admitió el despacho de diligencias (ej. admisión de la prueba vencido el término probatorio). Esto es, la limitación no se justifica cuando el elemento probatorio ha sido incorporado irregularmente. Ver DIAZ VILLASUSO, Mariano. Código Procesal Civil y Comercial de la Provincia de Córdoba, Advocatus, Córdoba, 2013.

30 PALACIO, Cfr. ob. cit., p.330.

31 El incidente de nulidad, también se encuentra previsto en sentido similar en el CPCC (art. 76-78).

32 RODRÍGUEZ JUÁREZ, Manuel, Incidentes, ( $1^{\circ}$ reimpresión), Ed. Mediterránea, Córdoba, 2010.

33 DÍAZ VILLASUSO, ob. cit., T. I, p. 701.
} 
la acción de amparo (art.7 de la ley 4915); testimonial excluida por parentesco (art.309 (PCCC); medio probatorio tendiente a sustituir otro que específicamente corresponda (art.318 del CPCCC), etc. De allí que, conforme esta explicación, la prueba prohibida comprende aquellos supuestos previstos por una norma, sustancial o procesal.

En tal marco, teniendo en consideración que la prueba ilícita constituye una especie de prueba prohibida, el juez de advertir algún supuesto de ilicitud al momento de admitir el elemento probatorio impedirá su ingreso al proceso. No obstante, esto requiere de algunas precisiones: dado que la inadmisibilidad ${ }^{34}$ concierne a la forma, esto es a los requisitos procesales del medio probatorio, y surge directamente de la reglamentación legal, para efectuar una valoración al respecto se requiere de reglas que precisen en qué casos se está ante una prueba ilícita, lo cual arroja como antítesis ¿Qué ocurre cuando estás previsiones son genéricas?, que, por cierto, es lo habitual en el caso de normas constitucionales.

Indudablemente, atento el estado de evolución de la exigibilidad de los derechos constitucionales, y el importante reconocimiento constitucional -y a través de tratados internacionales- de derechos y garantías como el debido proceso o la protección de los derechos fundamentales, el hecho de no contar con previsiones especificas no es óbice para que se desconozcan disposiciones constitucionales. Lo cual, por otro lado, no implica negar que producto de su generalidad -entre otros aspectos- se requerirá de un mayor esfuerzo interpretativo.

Clarificado este aspecto, resta profundizar sobre el funcionamiento de estas disposiciones en la práctica. En este sentido, dado que el ordenamiento procesal recepta la libertad probatoria, el juicio de admisibilidad es forma ${ }^{35}$ por lo que el juez, salvo que se trate de un supuesto de ilicitud manifiesta, en la generalidad de los casos, no contará con elementos suficientes para resolver, de modo justificado, la inadmisibilidad de un elemento o la no producción de un medio de prueba, y ante una situación de duda lo admitirá, sin perjuicio que al momento de valorar el resultado probatorio esa información pueda ser excluida. ${ }^{36}$

A lo dicho, corresponde añadir que conforme el diseño del proceso el Juez de Conciliación y el Juez de Conciliación y del Trabajo -este último, conf. modif. introducida por la ley 10.596- no valora la prueba y un planteo de ilicitud implica valoración ${ }^{37}$ y, aún en los casos que se tramitarán por PDA, si bien el juez valorará la prueba lo efectuará en el momento procesal oportuno -al resolver-, por lo que el momento de la admisibilidad, en supuestos donde la ilicitud no surja patente, no resulta propicio para desestimar su ingreso al proceso sin afectar el derecho a probar.

\footnotetext{
34 El juicio de admisibilidad implica un análisis sobre si las pruebas fueron introducidas al proceso en tiempo oportuno; ofrecidas con las formalidades requeridas por la ley, o si lo hicieron quienes se encontraban autorizados para ello. TOSELLI, Carlos A.- ULLA, Alicia G., Código procesal del trabajo Ley 7987, Alveroni, Córdoba, 2012. p.303..

35 A diferencia, por ejemplo, del sistema estadounidense donde la calidad de la información que se incorpora al proceso se controla al momento de la admisión, ello -entre otras razones- dado que el órgano que resuelve es un jurado lego, que no tiene obligación de justificar sus decisiones.

36 Juzgado de Conciliación de $1^{\circ}$ Nominación, Córdoba, autos "Szilagyi Cazzulani, María Ángeles C/ Be There Argentina S.A. y Otro Ordinario - Despido", A.I. 90, 5/6/2017:“(...) la eventual exclusión de la prueba de que se trata en ocasión de hacer el juicio de admisibilidad que cabe a este Tribunal, con las limitaciones expuestas supra, entiendo aparece prematura y vulneratoria del derecho de defensa en juicio y del principio de libertad probatoria".

37 Juzgado de Conciliación de $1^{\circ}$ Nominación, Córdoba, autos: "Szilagyi Cazzulani”, cit.: "Este Tribunal, al serle ofrecida la documental de que se trata, dispuso su admisión a mérito de lo dispuesto por el art. 200. El recurrente afirma que dicha documental es ilícita toda vez que fue obtenida furtivamente, representando una traición en la confianza depositada en la actora, extremos que, estimo, no pueden ser discernidos en ocasión de verificar la admisibilidad de la prueba de que se trata sino a la hora de su valoración en la sentencia final, toda vez que la ilicitud no aparece patente cuando el que aporta la grabación es el propio interlocutor del diálogo grabado y esgrimido en el proceso en su propio beneficio". (El destacado nos pertenece).
} 
En este sentido, aunque refiriéndose al proceso penal -pero de algún modo extensible al ámbito laboral atento el modo como están estructurados ambos procesos-, Hairabedian ${ }^{38}$ refiere que un elemento probatorio manifiestamente ilícito si bien puede ser rechazado tras su ofrecimiento, en la mayor parte de los casos ello no ocurre, ya que generalmente la ineficacia es una cuestión que se analiza al valorar la prueba. De allí que la cuestión de la prueba ilícita, si bien puede resolverse tempranamente a través de la inadmisibilidad, en la práctica puede que ello no ocurra hasta el final de proceso.

No obstante, respecto de los medios de prueba a producirse, el juicio de admisibilidad constituye un momento propicio para prevenir futuras impugnaciones ${ }^{39}$, en tanto es el momento oportuno para controlar la información que se pretende obtener con su producción, como por ejemplo a través de los puntos de pericia o la información requerida a una empresa de telefonía o de internet, a efectos de prevenir que se ordenen medidas con potencialidad para afectar derechos de las partes o de terceros.

Por otra parte, este accionar que está previsto en el ordenamiento (art. 33 LPT) $\mathrm{y}$, actualmente, ha sido reforzado con la modificación introducida por la ley 10.596 en relación a la facultad de los magistrados. Ello, sin dejar de lado los requerimientos materiales de las oficinas judiciales para poder efectuar una análisis pormenorizado de los escritos de ofrece prueba de cada expediente.

\section{ii) Decreto de prueba: recursos}

Al proveerse la prueba ofrecida, en contra de la resolución que deniegue o sustituya algún medio de prueba o elemento probatorio procederá el recurso de reposición y apelación (art.53 LPT). ${ }^{40}$ Sin embargo, para el tema que nos ocupa, resulta de interés indagar sobre el modo de proceder cuando se genera el supuesto de hecho inverso al previsto en aquél enunciado normativo, esto es cuando la parte contraria -a la que se le inadmitió la prueba-, se considera agraviada en función del contenido del elemento probatorio ofrecido o medio de prueba solicitado.

En este sentido, la vía impugnativa prevista es el recurso de reposición, medida que se interpone ante el mismo órgano que dictó la resolución atacada (art. 91 LPT), y solo en los supuestos en que se alegue gravamen irreparable la parte afectada puede interponer recurso de apelación (art. 94 LPT), el cual será resuelto por la Cámara Única del Trabajo (CUT), a través de sus Salas, luego de expedirse el a quo respecto de su admisibilidad formal, decisión -admisibilidad formal-, que, a su vez, tiene que ser mantenida por el ad quem (art. 89 LPT).

\footnotetext{
38 HAIRABEDIÁN, ob. cit., p.71.

39 En el marco de un proceso laboral, durante el diligenciamiento de la prueba se generó un desacuerdo en torno a la información que el actor le requería al perito (puntos de pericia): la recuperación del buzón de email del servidor de la empresa de excompañeros de trabajo. El perito se opuso explicando que al ser los excompañeros del actor ajenos al proceso necesitaba su autorización o, en su defecto, una orden judicial. Cámara Ûnica del Trabajo, Córdoba, Sala X, “Ferrero Manfredo Stelvio c/ Prominente SA - Ordinario - Despido - Apelación en Ordinarios", A.I. n 9, 5/2/2014.

40 La Jueza de Conciliación de $5^{\circ}$ Nominación, Córdoba, al proveer la prueba, desestima el pedido de exhibición de legajos de compañeros de trabajo del actor, quien interpone recurso de reposición con apelación en subsidio, y ambos son desestimados. El segundo, con sustento -en lo relevante para el tema que nos ocupa- en que la decisión no causaba gravamen irreparable, dado que la mayoría de los compañeros del trabajador, cuyo legajo pretendía el actor que la demandada exhibiera, se encontraban ofrecidos como testigos. El actor interpone recurso directo, y la Cámara Única del Trabajo, Córdoba, hace lugar y ordena se dé trámite al recurso de apelación. Al resolver de ese modo, refirió que "El artículo 53 de la LPT (...) habilita expresamente la vía intentada en los presentes obrados, al tratarse de un recurso frente a la denegatoria de prueba. Luego, dándose los requisitos legales, la a quo al no conceder el recurso de apelación interpuesto en subsidio, se ha excedido en el control de admisibilidad formal del recurso conforme las atribuciones previstas en la ley adjetiva. La norma contempla expresamente la vía impugnativa con independencia de la existencia gravamen irreparable". Cámara ünica del Trabajo, Córdoba, Sala II, en "Bogado Guillermo c/ F.C. Argentina S.A. - Ordinario- Despido - Recurso Directo (Expte: 700 6902)", A.I. n 172, 24/8/2018.
} 
En este sentido, la procedencia del recurso de apelación encuentra sustento en lo previsto en el art. 94 LPT. Esto es, si la ley no prescribe expresamente la recurribilidad de la decisión, en principio, ella no resulta apelable, a excepción que se verifique el supuesto en el cual lo resuelto cause gravamen irreparable.

\section{iii) Incidencias durante la producción del medio de prueba}

En relación a las incidencias durante la producción de prueba relacionada con EPI, cabe efectuar algunas precisiones: atento la estructura del proceso, instancia única desdoblada en dos etapas -a excepción de las causas que se tramitarán por PDA- los medios de prueba que se producen ante el Juez de Conciliación -con anterioridad a la audiencia de vista de la causa que tiene lugar ante la CUT-, son la pericia, el reconocimiento o exhibición de documentación y la informativa.

A la vez que, el reconocimiento u exhibición tienen lugar en el marco de una audiencia, y aun cuando el enunciado normativo no lo explicite la doctrina ha entendido que se aplica de modo análogo a la audiencia de prueba lo previsto para la audiencia de conciliación o de vista de la causa (art. 34 inc. 1), por lo tanto las impugnaciones que aquí pueden presentarse se resuelven en la audiencia, lo cual reduce el análisis propuesto a la producción de prueba pericial e informativa, y a las incidencias que allí pudieren tener lugar.

Esto vinculado al impacto de la tecnología en la actividad probatoria, nos reconduce específicamente a prueba pericial informática ${ }^{41}$. En este sentido, conforme lo previsto en el art. 279 CPCCC -de aplicación supletoria al ámbito laboral-, al dictamen pericial pueden formulársele objeciones de índole formal o, bien, a su contenido.

Las primeras en tanto refieren a la realización del acto pericial se canalizan a través del incidente de nulidad, como por ejemplo la falta de notificación de las diligencias periciales o de la agregación del dictamen; que el perito se haya pronunciado sobre puntos no propuestos por las partes ni ordenados por el juez, etc.

Por otro lado, si lo cuestionado es el contenido del dictamen, ya sea por un vicio en el razonamiento o en el método utilizado para llegar a las conclusiones formuladas, corresponde esperar hasta los alegatos para exponer las quejas. Por lo que esta impugnación no tiene sustanciación y los cuestionamientos son tenidos en consideración recién en la sentencia. ${ }^{42}$

En síntesis, conforme el vicio que se denuncie será el momento para efectuar la impugnación ${ }^{43}$ : las objeciones formales concernientes a la realización de la pericia se

41 Juzgado de Conciliación de $8^{\circ}$ Nominación, Córdoba, al resolver reposición en autos "Ortiz Santiago Andrés c/ Telenco S.A. Y Otros - Ordinario Estatutos Especiales", A. I. n 70, 22/5/2018.

42 DÍAZ VILLASUSO, conf. ob. cit. ,T. II, p.130.

43 Cámara Única del Trabajo, Córdoba, Sala II, al resolver recurso directo en autos "Oliva, Cristian M. c/ Municipalidad de Córdoba - Ordinario Accidente",A.I. $n^{\circ}$ 316,2/8/2017: "Uno de los cuestionamientos, se vincula con el pedido de nulidad de la pericia médica oficial (...) con fundamento en que este carece de asidero científico y jurídico, y de razones para sostener que la incapacidad del actor, resulta preexistente. En cuanto a la vía del incidente de nulidad, se debe indicar que ella se relaciona con los cuestionamientos formales del acto pericial, tales como, carencia de título habilitante, falta de notificación del inicio pericial etc., aspectos no denunciados como vicio por el impugnante. En cuanto a los cuestionamientos sobre el fondo, es decir, sobre los fundamentos o conclusiones del dictamen pericial, el Art. 279 del CPCC dispone en la parte que nos concierne: '[...] Cualquier objeción que se formule sobre las conclusiones o fundamentos deberá producirse en los alegatos y será considerada en la sentencia, sin perjuicio de lo dispuesto en el párrafo siguiente. El Tribunal podrá, de oficio o a petición de parte, disponer que se amplíe el dictamen si lo creyere deficiente u ordenar que se nombren otros peritos, sin recurso alguno'. Se advierte que la norma (...) determina dos tipos de impugnaciones al informe pericial, con momentos diferentes para su introducción en el proceso, luego de ser notificado el proveído de incorporación de aquél. Los referidos a cuestiones procedimentales ya relacionados, que puedan ser objeto de la pretendida sanción de nulidad y los que versan sobre las conclusiones o fundamentos del dictamen, cuyos motivos pueden diferirse hasta el momento de los alegatos, pues deben ser considerados por el Tribunal de mérito, en oportunidad de sentenciar. Trasladando los conceptos 
canalizan a través del incidente de nulidad, mientras que las objeciones sobre los fundamentos dados por el experto o sobre la eficacia de su labor se tratan al dictar sentencia, en cuyo caso los motivos pueden diferirse hasta alegatos, pues serán considerados al dictar sentencia, no siendo ello impedimento para que en el supuesto que sean introducidos con anterioridad se ordene su diferimiento para la oportunidad procesal indicada.

\section{iv) Exclusión probatoria}

En el orden normativo, HAIRABEDIÁN ${ }^{44}$ distingue entre los sistemas que han adoptado alguna regulación específica respecto a la exclusión probatoria y los que no, lo cual, indudablemente, incide en la aplicación del instituto. ${ }^{45}$

En la Constitución Nacional (CN) no se prevé expresamente el valor de la prueba ilícita y los pactos internacionales, incorporados a ella, tampoco poseen normas generales sobre la exclusión de prueba inconstitucional, habiéndose contemplado solo algunas hipótesis específicas ${ }^{46}$. Mientras que en el orden local, en la Constitución de la Provincia de Córdoba (CPC) se dispone que los elementos obtenidos vulnerando garantías constitucionales carecen de eficacia probatoria, situación que se extiende a aquéllos que no hubiesen podido ser obtenidos sin su violación (art. 41). ${ }^{47}$

Profundizando, si bien, esta problemática puede haber alcanzado mayor desarrollo en el derecho procesal penal, por los objetivos y facultades del Estado en ese proceso, ello no la hace una institución propia de esa área del derecho.

Especialmente, cuando es un dato de la realidad procesal, en los últimos años, el empleo de información generada, transmitida o almacenada por medios técnicos, ligada a bienes jurídicos protegidos de las partes (ej. inviolabilidad de la correspondencia, secreto de las comunicaciones, etc.) para probar los hechos objeto de sus pretensiones.

En otras palabras, sin desconocer que los caracteres del proceso penal se alejan de proceso laboral, desde una mirada que se sustenta en el respeto de los derechos constitucionales entre particulares, el efecto de ineficacia del resultado probatorio que implica la regla de exclusión puede ser aplicado al ámbito laboral. Primordialmente en aquellos casos en los que no surge con claridad la ilicitud para declarar la inadmisibilidad del elemento probatorio o, bien, los presupuestos para plantear las vías de impugnación previstas en el ordenamiento (recurso o incidente) con anterioridad a la sentencia.

\footnotetext{
enunciados al análisis del acápite recursivo, se advierte que el discurso del presentante se dirige a embatir, tanto los fundamentos como las conclusiones del dictamen pericial, sin exponer un vicio susceptible de la sanción que pretende, cuyo análisis se encuentra reservado al Tribunal de sentencia, por lo que el recurrente carece de agravio y, en consecuencia, el recurso de apelación ha sido erróneamente concedido por la a quo”. En sentido similar, Cámara Única del Trabajo, Córdoba, Sala II, al resolver recurso de apelación en contra del auto interlocutorio dictado por el Juez de $1^{\circ}$ Nominación de Villa Carlos Paz, en autos "Albornoz Jessica Roxana c/ Organización Hotelera del Sur S.A. - Recurso de Apelación", A.I. 320, 21/12/2018.

44 HAIRABEDÍAN, ob. cit., p.43.

45 En el ámbito regional, hace unos años, producto de la reforma del proceso laboral que tuvo lugar en Chile, surgió -entre otros- un debate sobre el alcance de la exclusión probatoria en ese proceso. En una breve síntesis, en ese país, si bien diversas resoluciones habían optado por no valorar pruebas que contravenían garantías fundamentales, no había una norma especifica que así lo establezca hasta que, como resultado de aquella reforma, se previó que “(...) carecerán de valor probatorio y, en consecuencia, no podrán ser apreciadas por el tribunal las pruebas que las partes aporten y que se hubieren obtenido directa o indirectamente por medios ilícitos o a través de actos que impliquen violación de derechos fundamentales” (art. 453 del CT). JARA BUSTOS, ob. cit.

46 En las Convenciones de Derechos Humanos el único supuesto previsto sobre exclusión de prueba obtenida ilícitamente es la confesión bajo coacción (CADH 8.3).

47 "Los actos que vulneren garantías reconocidas por esta Constitución carecen de toda eficacia probatoria. La ineficacia se extiende a todas aquellas pruebas que, con arreglo a las circunstancias del caso, no hubiesen podido ser obtenidas sin su violación y fueran consecuencia necesaria de ella".
} 


\section{v) Nulidad de la sentencia vía recurso de casación}

Finalmente, resta mencionar que los titulares del derecho a recurrir una decisión por vía de casación pueden invocar como motivo la inobservancia de normas que prescriben el modo en que debe desarrollarse el proceso.

En este sentido, conforme lo previsto en el art.99 inc.2) LPT el recurso de casación puede ser interpuesto ante la inobservancia de las normas establecidas bajo pena de inadmisibilidad, caducidad o nulidad siempre que el recurrente hubiere reclamado oportunamente la subsanación del defecto -si era posible-, o hubiese hecho protesta de recurrir en casación.

Lo habitual es que se denuncie la observancia de alguno de los mandatos contenidos en el art.65 LPT, norma que regla las causales de nulidad de la sentencia. En el caso que nos ocupa adquiere relevancia lo previsto en el inc. 1) en tanto establece como presupuesto de nulidad de la sentencia que "se base en elementos probatorios no incorporados legalmente al debate, salvo que carezcan de valor decisivo".

Al respecto, DÍAZ ${ }^{48}$ refiere que la fundamentación de la denuncia sustentada en este vicio requiere observar varios recaudos: en primer orden, el casacionista no debe haber causado el vicio, esto es no debe haber sido la parte que introdujo la prueba ilegalmente al proceso; tampoco debe haber mediado consentimiento del vicio, esto es, debe haberse opuesto a su incorporación en forma oportuna.

Asimismo, corresponde considerar el carácter dirimente del vicio, esto es, debe demostrar que el defecto es la causa determinante de la decisión y que, eliminado el quebrantamiento, la decisión no se sostiene. Así, el enunciado empleado prevé que si dicha prueba irregularmente analizada no ha tenido incidencia decisiva en la fundamentación de la resolución, carece de relevancia para modificarla. ${ }^{49}$

Esto sin desconocer que el tribunal ante la afección de derechos constitucionales, conforme lo previsto en el art.33 LPT, que si bien no refiere a la actividad probatoria de modo especifico se trata de una directiva general, puede declarar, de oficio y en cualquier estado de la causa, la nulidad.

\section{Conclusiones}

En una línea de investigación que relaciona por un lado, el impacto tecnológico en el trabajo, como actividad humana, y en el derecho del trabajo, como disciplina jurídica y, por otro, lo atinente a la efectividad en el proceso de los derechos constitucionales, este trabajo, a partir del análisis de planteos en causas que tramitan ante el fuero laboral Córdoba, sistematiza problemas relativos a la validez de la prueba a efectos de explicitar la respuesta proporcionada por el ordenamiento procesal.

A tales efectos, luego de precisar algunos aspectos conceptuales, se trabajó sobre el alcance del derecho a probar, como sobre los institutos procesales dispuestos para encausar los planteos sobre prueba ilícita, conforme el momento en que se presentan, con especial referencia a la exclusión probatoria, su recepción normativa y aplicación a procesos en los que no está regulada de modo específico.

\footnotetext{
48 DÍAZ Silvia L., "Recurso de Casación”, Inédito. Material proporcionado por la autora.

49 En sentido similar, TSJ en autos "Camargo Plaza, Ada c/ Yolanda Ames y otros - Demanda y sus acumulados - Recurso de casación", A.I. n 704,17/11/2000, en TOSELLI- ULLA, ob. cit. p.345.
} 
En este sentido, no hay discusión que los ordenamientos jurídicos modernos -al menos de Occidente- frente al derecho a la jurisdicción o acceso a la justicia protegen valores extraprocesales, generalmente positivizados en normas con jerarquía constitucional, y para preservarlos limitan, normativamente, el derecho a probar disminuyendo o, incluso, anulando las posibilidades de averiguación de los hechos.

En tal marco, los planteos relacionados con la prueba ilícita no constituyen una novedad en la praxis procesal, y si bien se trata de un tema que ha alcanzado mayor desarrollo en el derecho procesal penal, especialmente producto de la intervención del Estado -a través de sus órganos de investigación y persecución penal- en aquél proceso, lo que ha dado lugar al desarrollo de la regla de exclusión probatoria y sus derivados -como la exclusión de prueba derivada- con un importante empleo en las resoluciones judiciales y, consecuente, recepción normativa en algunos ordenamientos.

Ello no impide visibilizar el desarrollo producido en otros procesos donde se han establecido normas tendientes a impedir la admisibilidad de elementos de prueba o declarar la ineficacia de prueba que incumplía reglas procesales propias de cada medio probatorio o, bien, afectaba normas sustanciales.

Así, en el proceso civil -de aplicación supletoria al proceso laboral (art. 114 LPT)si bien puede no haber normas que regulen de modo de modo específico la prueba ilícita, son tradicionales las disposiciones relativas a la inadmisibilidad de prueba prohibida (art.199 CPCC; art.83 sexies LPT; art. 378 CPCCN; art. 376 CPCC Bs. As., etc.). Lo cual, aun con la dificultad que a nivel interpretativo genera la aplicación de normas constitucionales, -entre otros aspectos- atento su generalidad, no implica que estos mandatos no resulten comprendidos por la previsión de inadmisibilidad, lo que tempranamente -en el iter procesal- impide el ingreso al proceso de elementos probatorios que hayan sido obtenidos infringiéndolas (prueba ilícita).

Sin embargo, se presentan circunstancias, como por un lado, un reconocimiento amplio del derecho a probar y, en consecuencia, libertad probatoria y, por otro, atento la estructura del proceso donde el Juez de Conciliación no valora la prueba -y en un futuro el Juez de Conciliaron y del Trabajo no lo hará al momento de la admisibilidad-, por lo que salvo que se trate de una ilicitud manifiesta el material ofrecimiento es admitido y el problema de la ilicitud se traslada a otro momento procesal ${ }^{50}$.

En función de ello, en este trabajo se han desarrollado, de modo cronológico, las diferentes vías previstas -además de la ya referida- para evacuar planteos relativos a la prueba ilícita (recursos e incidencias), considerando especialmente la excusión probatoria como instituto adecuado para excluir de la valoración de la prueba, en el momento inmediato anterior a la sentencia, aquella información que haya sido incorporada o producida infringiendo normas constitucionales.

Ello teniendo en cuenta que, si bien los estudios sobre el proceso laboral puede que no lo hayan desarrollado en profundidad, lo cierto es que se trata de un instituto tradicional en la teoría procesal con la particularidad que, actualmente, en el ámbito

50 Lo expuesto sin perjuicio que, respecto de los medios de prueba que se pretenden producir (ej. pericia), el juez posee facultades -art. 33 LPT, y ratificadas por las previsiones de la ley 10.596- para controlar lo ofrecido a efectos de solicitar aclaraciones o encauzar la información requerida y, de ese modo, prevenir futuras impugnaciones. Posibilidad permitida por el ordenamiento que requiere de previsiones materiales adecuadas. 
laboral producto del empleo de dispositivos tecnológicos, tanto para ejecutar la prestación (computadora, teléfono, etc.) como en el contexto donde la prestación de servicios tiene lugar (dispositivos que captan, procesan y almacenan datos de la persona que trabaja), está adquiriendo importante relevancia.

Finalmente, desde lo normativo, si bien en el ordenamiento procesal laboral directamente, o vía remisión al proceso civil, no se ha previsto norma específica al respecto51, resulta relevante lo establecido en la Constitución de la Provincia al prever la ineficacia de actos que vulneren garantías constitucionales como la información de ellos derivada. A la vez que, en la praxis, tal vez sin referir de modo explícito a la regla de exclusión, se resuelve excluir de la valoración aquella prueba que haya sido obtenida o producida violando derechos reconocidos constitucionalmente ${ }^{52}$.

51 A diferencia del caso español, por ejemplo, en tanto en la Ley Orgánica del Poder Judicial (LOPJ) se establece que "En todo tipo de procedimiento se respetarán las reglas de la buena fe. No surtirán efecto las pruebas obtenidas, directa o indirectamente, violentando los derechos o libertades fundamentales" (art. 11. 1.). 6/1985, del 1 de julio. (El destacado nos pertenece).

52 En el caso se analiza la eficacia probatoria del testimonio de un investigador privado como de las filmaciones efectuadas por éste, ofrecidas por la demandada a efectos de acreditar un despido. El tribunal, restó eficacia probatoria a las filmaciones obtenidas subrepticiamente y, en consecuencia, determinó que la causa del despido no había sido probada. Para decidir de ese modo argumentó que: "En el procedimiento laboral rige el principio de libertad probatoria, lo que supone que todos los medios de prueba son admitidos y su licitud se presume, sin embargo esta regla reconoce como excepción aquellos que hayan sido obtenidos de modo ilegítimo o que resulten lesivos de la dignidad, la libertad de la persona o de sus derechos fundamentales, tutelados por las normas constitucionales y legales. En el caso de autos el DVD en examen, conforma un medio probatorio obtenido subrepticiamente, sin participación del señor (...), ni de un juez que la supla. De tal manera se incurre en una vulneración del derecho a la intimidad y de la garantía de defensa, que impide se lo evalúe como elemento de convicción. En tales condiciones, el Tribunal no se encuentra autorizado para sustentar su decisión en material probatorio que se encuentra viciado por haber sido obtenido en violación de las formas procesales para su recolección, esto es, sin ajustarse al principio de formalidad y legitimidad de la prueba", Cámara Única del Trabajo, Córdoba, Sala II, “Carranza Elvio R. c/ Veizaga J. y otro - Ordinario - Despido", Sentencia $n^{\circ} 90,10 / 11 / 2009$. 


\section{Bibliografía consultada.}

- Castro Argüelles, Ma. Antonia, "Derechos fundamentales en el proceso laboral" (ponencia). XXIV Congreso Nacional de Derecho del Trabajo y de la Seguridad Social. Pamplona, 29-30 de mayo de 2014. Consultado en sitio web: http://fundacion.usal.es/ aedtss/images/04_Maria_Antonia_Castro.pdf

- Díaz, Silvia L., "Recurso de Casación". Inédito.

- Diaz Villasuso, Mariano. Código Procesal Civil y Comercial de la Provincia de Córdoba, Advocatus, Córdoba, 2013.

- Gascón Abellán, Marina, Los hechos en el derecho, Marcial Pons, Madrid, 2004.

- Hairabedián, Maximiliano, Eficacia de la prueba ilícita y sus derivaciones en el proceso penal. ( $\left.2^{\circ} \mathrm{Ed}\right)\left(1^{\text {a }}\right.$ Reimpresión) Ad Hoc, Buenos Aires, 2016.

- Jara Bustos, Francisco. "Prueba ilícita en materia laboral, la regla de exclusión más amplia del derecho chileno" (p. 113 a 128), en Revista Chilena de Derecho del Trabajo y de la Seguridad Social, Vol. 2, N 3, 2011.

- Kielmanovich, Jorge, "Algo más sobre la ineficacia de la prueba ilícita". Cita on line: 0003/008557 20013501.txt. Doctrina.

- Midon, Marcelo S., Pruebas ilícitas, Ed. Jurídicas Cuyo, Mendoza, 2005.

- Palacio, Lino E., Código Procesal Civil y Comercial de la Nación, Abeledo Perrot, Buenos Aires, 2003.

- Pellegrini Grinover, Ada, "Pruebas ilícitas", en Derecho Penal. Derecho Procesal Penal, Abeledo Perrot, Buenos Aires, 1997.

- Quadri, Gabriel, "Los mensajes de texto como prueba en el proceso civil". Jurisprudencia Argentina. 2015, V.2. Consultado en Thomson Reuters. Cita Online: AP/DOC/381/2015. "La prueba electrónica en la reforma al proceso laboral bonaerense", en La Ley BA 2018 (diciembre) 1.

- Rodríguez Juárez, Manuel, Incidentes (1º reimpresión), Ed. Mediterránea,Córdoba, 2010.

- Taruffo, M., La prueba, Marcial Pons, Madrid, 2008.

- Toselli, Carlos A. - ULLA, Alicia G., Código procesal del trabajo Ley 7987, comentado y anotado con jurisprudencia ( $2^{\circ}$. Ed. ampliada y actualizada. $2^{\circ}$ reimp.), Alveroni, Córdoba, 2012.

- Vázquez, Carmen, "La prueba informática desde la teoría racional de la prueba" (p. 326-340), en XII Congreso Iberoamericano de Derecho e Informática. Zaragoza; FIADI, 2008

"La prueba pericial en la experiencia estadounidense". Conferencia para Cátedra de Cultura Jurídica. Universidad de Girona. 31/01/17. https://youtu.be/ IBJ-bhYVyA8 